\title{
Bureaucracy denies grants
}

\section{Tokyo}

MANY Japanese researchers are, for practical purposes, being denied access to funds available from the country's imaginative Human Frontier Science Program, based in Strasbourg, France. This came to light last week, in a further illustration of how Japan's bureaucracy can shoot its own ambitions in the foot.

In the mid-1980s, researchers belonging to the Ministry of International Trade and Industry (MITI) helped to formulate the programme, which supports international research on the brain and molecular biology. At that stage, they expected themselves to benefit from the programme. But it has now emerged that MITI researchers and thousands of others at national research laboratories are in effect barred from receiving Frontier grants by extremely rigid bureaucratic regulations.

One result is that there has been a dramatic fall in the number of applicants for Frontier grants from Japan's national laboratories in the latest round of applications, completed last September.

This is not the first time that such problems have come to light. Last year, researchers from Japan's national universities who were awarded Frontier grants were dismayed to find that, under government regulations, they had to pay about 50 per cent personal income tax on their awards. After months of wrangling between the government ministries and agencies, Frontier grants were eventually declared tax exempt under a special regulation by the Ministry of Finance (Nature 347, 703; 1990).

But Kenji Goto, deputy director of MITI's Frontier office, now says that "this was only the first chapter". The new Ministry of Finance regulation may have solved the problem for researchers at universities, but there is no mechanism by which those at national research laboratories can receive Frontier grants.

For researchers at national laboratories, Frontier grants would first have to go into a general account for all of Japan's ministries and government agencies and then be fed indirectly to the national laboratory concerned.

The rigid limits on ministry and agency spending decreed by the Ministry of Finance make this impractical. A recipient ministry would be able to receive its grant only by making cuts elsewhere in its spending. The confusion is especially ironical because the general account is also that from which general support for the Frontier programme is paid.

Goto and his colleagues at MITI's Agency of Industrial Science and Technology (AIST) have been labouring on this problem for the past two years. On 18
June last year, they issued a directive to AIST researchers suggesting that those seeking Frontier grants should organize their international research teams as "separate legal entities". Successful applicants would then be able to carry out "joint research" with the new entity. No money would change hands, but researchers would be allowed to "borrow" hardware bought with Frontier grants.

Some researchers are dismayed by this advice. Youji Mitsui, head of the Cell Science and Technology Division of AIST's Fermentation Research Institute in Tsukuba who, together with Tomoh Masaki of the University of Tsukuba, has won international recognition for pioneering research on endothelin peptides (see, for example, Nature 348, 673; 1990), has decided it would be a waste of time for him to apply for a Frontier grant.

He says that he does not need hardware, but chemicals, reagents and salaries for assistants. He also says that setting up an international research team composed of people from several different countries as a "separate legal entity" would cause tremendous headaches and a great deal of embarassment if it failed.

Mitsui is not alone. Goto says that 15-20 people from Japanese national laboratories applied for Frontier grants in the first round of applications in 1989 , but that the number plummeted to "two or three" in 1990.

Goto and his colleagues at MITI realize that their solution, which tries to work within the present system, is by no means ideal. The real need is for a complete overhaul of the mechanism of research funding at Japan's national research institutes to create more flexibility. But that would forbiddingly require coordination of all ministries and agencies involved, including MITI, the Science and Technology Agency (STA), the Ministry of Health and Welfare, the Ministry of Agriculture, Forestry and Fisheries and the Ministry of Posts and Telecommunications.

STA is the lead agency for the Frontier programme, contributing 60 per cent of the cost. But STA officials, who would have to push for change, are reluctant to admit that there is a problem.

Ryuji Shimoda, director of STA's Frontier office, says that researchers at national institutes may have been discouraged from applying in 1990 by the intense international competition for Frontier grants, poor English ability and by the example of the 20 or so applicants in 1989 , all of whom failed. He accepts that payment problems may also matter, but says that because no researcher from a national laboratory has yet won a Frontier grant, STA has "not yet looked into the matter in detail".

David Swinbanks

\section{One tap is closed, but another is opened}

\section{Tsukuba}

RESEARCHERs at MITI's Agency of Industrial Science and Technology (AIST) may be shut out from the Human Frontier Science Program, but they are now eligible for grants from a new domestic grant scheme modelled after Frontiers. The programme, run by AIST, was introduced in 1988, and is the first in Japan to have a western-style peer review system.

The grants, which are for research on "biological functions", are small, ranging from 3 to 13 million yen $(\$ 23,000-\$ 100,000)$ a year for three years. But researchers can hold more than one grant simultaneously. There are about ten awards each year.

Youji Mitsui, of AIST's Fermentation Research Institute in Tsukuba, currently has three grants which help support a team of about 30 researchers and technicians drawn from his institute, universities and industry. Using an immortal endothelial cell line, the group is investigating the effects of endothelin on smooth muscle contraction, the recognition of cancer cells by endothelial cells in the walls of blood vessels, and gene expression of vasoactive intestinal contractor (VIC), a peptide very similar to endothelin that was discovered by Mitsui's group.
Similarly, a group led by Shigeru Yamane, chief of the Neuroscience Section of AIST's Electrotechnical Laboratory in Tsukuba, has more than one grant to investigate facial and colour recognition in the monkey brain and to store a complete map of a monkey brain in a Macintosh computer in the form of magnetic resonance images and histological sections.

Hiroshi Uemura, senior researcher of AIST's National Chemical Laboratory, who helped formulate the new grant programme, claims that it is unique for AIST because grant applications are screened by scientists both within and outside AIST, and not by government officials. Furthermore, rejected applicants receive an explanation for why their applications are turned down, something normally unheard of in Japan.

Because of the recent fluctuation in the yen-dollar exchange rate, AIST has been able to boost the budget for the programme in 1991 by nearly 20 per cent to 288 million ( $\$ 2.2$ million) by drawing on funds originally intended for the Frontier programme. Even so, AIST researchers say that the budget needs to be at least doubled to have a significant impact. 